\title{
In silico Screening and Identification of Natural Compound Sophoraflavanone G as Potential Human Sodium-Glucose Cotransporter 2 Inhibitor
}

\author{
Wasimuddin Salaudden ${ }^{1}$, Irfan Navabshan ${ }^{2}$ (D), Subhamoy Banerjee ${ }^{1, *(D)}$ \\ 1 School of Life Sciences, B. S. Abdur Rahman Crescent Institute of Science \& Technology, Vandalur, Chennai - 600048 , \\ India; swasim0397@gmail.com (W.S.); subhamoy.sls@crescent.education (S.B.); \\ 2 School of Pharmacy, B. S. Abdur Rahman Crescent Institute of Science \& Technology, Vandalur, Chennai - 600 048 , \\ India; irfan@crescent.education (I.N.); \\ * Correspondence: subhamoy.sls@crescent.education;
}

Received: 18.01.2021; Revised: 25.02.2021; Accepted: 2.03.2021; Published: 7.03.2021

\begin{abstract}
Type 2 diabetes mellitus (T2DM) is characterized by insulin resistance, and it is hitherto incurable. Among different therapeutic modalities, glucose co-transporter (SGLT) inhibitors have gained prominence. In the current study, we have screened natural compounds as potential SGLT inhibitor and compared with conventional gliflozin drugs. We have selected human SGLT 1 and 2 sequences modeled by homology modeling using SWISS-MODEL server, stability analysis was performed in silico. We used CDOCKER to dock the selected gliflozin drugs and natural compounds with SGLT 1 and 2. We further checked adsorption, distribution, metabolism, excretion, and toxicity using ADMETSAR tools and identified Sophoraflavonone G as a potential natural compound with good binding energy and drug-like characteristics. The molecular dynamic simulation revealed sophoraflavonone G binds with SGLT2 and forms a stable complex.
\end{abstract}

Keywords: sodium glucose cotransportar; Sophoraflavonone G; CDocker; gliflozin; admetSAR.

(C) 2021 by the authors. This article is an open-access article distributed under the terms and conditions of the Creative Commons Attribution (CC BY) license (https://creativecommons.org/licenses/by/4.0/).

\section{Introduction}

Diabetes is a metabolic disorder that affects hundreds of millions of people globally. Type 2 diabetes mellitus (T2DM) is commonly found among diabetic patients and it is characterized by reduced insulin secretion by $\beta$ cells of Islets of Langerhans and insulin resistance [1], which results in hyperglycemia, delayed or impaired wound healing, diabetic retinopathy, diabetic nephropathy, diabetic neuropathy, etc., among multiple other complications [2]. Diabetes is an incurable disease, but its progression can be controlled. If unchecked, diabetes may cause stupor, coma, and even death due to multiple other complications. Since diabetes may happen due to multiple causes, there is no complete cure. Instead, drugs are designed to target different pathways or enzymes or receptors to keep the glucose level checked. T2DM results in major metabolic imbalance and activation of different inflammatory pathways [1]. A genome-wide analysis study (GWAS) identified 400 associated gene variants. The conventional treatment of T2DM includes a) insulin therapy where external insulin is administered for a therapeutic purpose [3], b) sulfonylurea used to stimulate pancreatic $\beta$ cells to secrete insulin [4], c) $\alpha$-glucosidase inhibitor, which delays carbohydrate absorption by small intestine [5], d) biguanide which inhibits hepatic 
neoglucogenesis process (e.g., metformin) [6], e) Thiazolidinesdions which is a PPAR $\gamma$ activator [7], f) dopamine antagonist [8], g) dipeptidyl peptidase inhibitor [9, 10], h) sodiumglucose co-transporter (SGLT) inhibitors [11-13].

Sodium-glucose co-transporters are found on the proximal convoluted tubule (PCT) of the nephron in the kidney [14]. The function of SGLT is the reabsorption of glucose, which works independently of insulin. For diabetic patients, due to SGLT activity, glucose is reabsorbed and transported back to the bloodstream, which results in elevated glucose in the bloodstream. There are six types of SGLTs are found in humans, of which SGLT 1 and 2 found mostly in the kidney and function as glucose transporter/absorber. Other than the kidney, SGLT2 is found in the liver, and SGLT1 is found in the kidney and many other organs like the brain, heart, intestine, trachea, testis, etc. SGLT3 is believed to act as a cellular glucose sensor and is found in the intestine, testis, lung, brain, etc. The function of SGLT 4, 5, and 6 is unknown, but they are found in different parts of the body [14]. In the kidney, SGLT 1 and 2 ratio is 1:10. Blocking of SGLT activities with selective inhibitors resulted in a significant decrease in glucose reabsorption, weight loss, and reduced HbA1C [15-17]. Gliflozine is a group of SGLT inhibitors that are designed to block glucose reabsorption at PCT. Different types gliflozine drugs are synthesized, and all drugs are not approved all over the world. Different gliflozine drugs like Canagliflozine, Dapagliflozine, Luseogliflozine, Empagliflozine, Topogliflozin have a higher affinity towards SGLT2 compared to SGLT1 [12, 15]. A post-market study shows urogenital tract infection, diabetic ketoacidosis as potential side effects $[18,19]$.

There are various natural compounds used to treat diabetes [20, 21]. Many plant-based natural compound structures have been elucidated, and some of their biological functions are known [22]. Few of the natural compounds are known to have nephroprotective activities $[23,24]$. Gliflozin drugs were originally designed based on the natural compound phorizin, obtained in the apple tree's bark [25]. Thus, screening for more plant-based natural compounds as SGLT2 inhibitors is continued [26, 27].

This study selected 10 different natural compounds proposed to have SGLT inhibition potential from literature and screened them using molecular docking analysis against SGLT 1 and 2. We used SWISS-MODEL [28] to model the proteins as the structure is unavailable. We also analyzed binding studies of selected gliflozine drugs (Canagliflozine, Dapagliflozine, Luseogliflozine, Empagliflozine, Topogliflozin) through molecular docking simulation. Then we checked the natural compounds for adsorption, distribution, metabolism, and excretion properties. We identified that Sophoraflavonone $G$ as the best compound based on combined docking and ADMET score. The molecular dynamic simulation study shows that the Sophorafalavonone G binds with SGLT2 and forms a stable complex.

\section{Materials and Methods}

\subsection{Structures of active compounds from plants.}

The plant phytochemicals we used in our study are obtained from the literature review [29]. The phytochemicals we are studying are as follows: (1) formononetin, (2) kurarinone, (3) pterocarpin, (4) sophoraflavanone G, (5) variabilin, (6) acerogenin A, (7) acerogenin B, (8) acerogenin C, (9) gneyulin A, (10) gneyulin B. These phytochemicals have demonstrated antidiabetic activity and supported by the literature [29] and were shortlisted to study the mode of action of these compounds with the active site of glucose co-transporters. Detailed information 
about the phytochemicals such as structure, IUPAC name, and the chemical formula was obtained from the PubChem database and mentioned in Table 1.

\subsection{Homology modeling.}

Homology modeling has been developed to build proteins from a sequence of amino acids to align with similar proteins with known structures (template) [30]. Denovo prediction technique can be used if there are no templates available, but if the sequence of amino acid is short for the de novo technique, a model cannot be built. To build a reliable three-dimensional structure of proteins, homology modeling plays a crucial role in silico methods [31]. We have used SWISS-MODEL (https://swissmodel.expasy.org/) to perform homology modeling of human SGLT1 and SGLT2.

Table 1. Phytochemical properties of plants.

\begin{tabular}{|c|c|c|c|}
\hline S.no & Compound & IUPAC Name & $\begin{array}{l}\text { Chemical } \\
\text { Formula }\end{array}$ \\
\hline 1 & Formononetin & '7-hydroxy-3-(4-methoxyphenyl) chromen-4-one' & $\mathrm{C}_{16} \mathrm{H}_{12} \mathrm{O}_{4}$ \\
\hline 2 & Kurarinone & $\begin{array}{l}\text { '(2S)-2-(2,4-[2])-7-hydroxy-5-methoxy-8-[(2R)-5-methyl-2-prop-1-en-2- } \\
\text { ylhex-4-enyl]-2,3-dihydrochromen-4-one' }\end{array}$ & $\mathrm{C}_{26} \mathrm{H}_{30} \mathrm{O}_{6}$ \\
\hline 3 & Pterocarpin & $\begin{array}{l}\text { '(1R,12R)-16-methoxy-5,7,11,19-tetraoxapentacyclo }\left[10 \cdot 8 \cdot 0 \cdot 0^{2,10} \cdot 0^{4,8} \cdot 0^{13,18}\right] \\
\text { icosa-2,4(8),9,13(18),14,16-hexaene' }\end{array}$ & $\mathrm{C}_{17} \mathrm{H}_{14} \mathrm{O}_{5}$ \\
\hline 4 & $\begin{array}{l}\text { Sophoraflavanone } \\
\text { G }\end{array}$ & $\begin{array}{l}\text { ‘(2S)-2-(2,4-dihydroxyphenyl)-5,7-dihydroxy-8-[(2R)-5-methyl-2-prop-1- } \\
\text { en-2-ylhex-4-enyl]-2,3-dihydrochromen-4-one’ }\end{array}$ & $\mathrm{C}_{25} \mathrm{H}_{28} \mathrm{O}_{6}$ \\
\hline 5 & Variabilin & $\begin{array}{l}\text { ‘(5Z)-5-[(6E,10E)-13-(furan-3-yl)-2,6,10-trimethyltrideca-6,10- } \\
\text { dienylidene]-4-hydroxy-3-methylfuran-2-one’ }\end{array}$ & $\mathrm{C}_{25} \mathrm{H}_{24} \mathrm{O}_{4}$ \\
\hline 6 & Acerogenin A & $\begin{array}{l}\text { '(12R)-2-oxatricyclo }[13.2 .2 .13,7] \text { icosa-1(17),3,5,7(20),15,18-hexaene- } \\
\text { 4,12-diol' }\end{array}$ & $\mathrm{C}_{19} \mathrm{H}_{22} \mathrm{O}_{3}$ \\
\hline 7 & Acerogenin B & $\begin{array}{l}\text { '(10S)-2-oxatricyclo }[13.2 .2 .13,7] \text { icosa-1(17),3,5,7(20),15,18-hexaene- } \\
4,10 \text {-diol' }\end{array}$ & $\mathrm{C}_{19} \mathrm{H}_{22} \mathrm{O}_{3}$ \\
\hline 8 & Acerogenin $\mathrm{C}$ & $\begin{array}{l}\text { '4-hydroxy-2-oxatricyclo [13.2.2.13,7] icosa-1(17),3,5,7(20),15,18-hexaen- } \\
\text { 12-one' }\end{array}$ & $\mathrm{C}_{19} \mathrm{H}_{20} \mathrm{O}_{3}$ \\
\hline 9 & Gneyulin A & $\begin{array}{l}\text { '4-[(E)-2-[(2R,3R)-3-(3,5-dihydroxyphenyl)-2-[(2R,3R)-2-(2,4- } \\
\text { dihydroxyphenyl)-3-(3,5-dihydroxyphenyl)-6-hydroxy-2,3-dihydro-1- } \\
\text { benzofuran-5-yl]-4-hydroxy-2,3-dihydro-1-benzofuran-6- } \\
\text { yl]ethenyl]benzene-1,3-diol' }\end{array}$ & $\mathrm{C}_{42} \mathrm{H}_{32} \mathrm{O}_{12}$ \\
\hline 10 & Gneyulin B & $\begin{array}{l}\text { ‘4-[(2R,3R)-3-(3,5-dihydroxyphenyl)-5-[(2R,3R)-3-(3,5-dihydroxyphenyl)- } \\
\text { 4-hydroxy-6-(6-hydroxy-1-benzofuran-2-yl)-2,3-dihydro-1-benzofuran-2- } \\
\text { yl]-6-hydroxy-2,3-dihydro-1-benzofuran-2-yl]benzene-1,3-diol' }\end{array}$ & $\mathrm{C}_{42} \mathrm{H}_{32} \mathrm{O}_{12}$ \\
\hline
\end{tabular}

Homology modeling is based on 4 main steps: Identification of proteins with experimentally solved protein structure (Search of template from databases); Modelling for a protein of interest (Selection of a template); Mapping of a target sequence and the template structure by manual adjustment and sequence alignment method; Evaluation of the derived protein.

Once the 3D-Structure of the proteins was generated, structural evaluation and $\begin{array}{lllll}\text { stereochemical analysis were performed using } & \text { SAVES }\end{array}$ (http://servicesn.mbi.ucla.edu/SAVES/). Ramachandran Plot was used to determine the accuracy of the structure and visualization was performed. 


\subsection{Binding Site Prediction.}

The cavities of the receptors are displayed as a set of points and a transparent sphere. If there is a ligand chain in the receptor-binding site cavity that is not detected, this method is known as Ligand Fit. It is based on user-defined binding site ligand may be minimized based on fixed and partial flexible receptors.

\subsection{Molecular Docking.}

The docking was carried out with DS 2017, which is a computational software analysis. There are several scoring functions available for evaluation. The high throughput screening is based on CDOCKER - which is based on aligning the ligand conformation of polar and nonpolar interaction sites of receptors known as hotspots [32]. The confirmation is generated using Catalyst. Minimization was done with CHARMm [33] since some poses may have hydrogen atoms close to receptors hotspots. Calculate ligand conformation, docks using conformation Libdock and minimize docked poses using CHARMm.

\subsection{ADMET-SAR.}

admetSAR (http://www.swissadme.ch/) plays a major role in screening new drugs, pesticides, different food additives and industrial chemicals [34]. It is especially useful to carry out toxicity analysis $[23,35,36]$. Calculation of phytochemical properties is important for filtering their "drug-likeness" and "lead likeness" and toxicity potential. In that situation, computer models establish a valid alternative to the experiments.

\subsection{Molecular Dynamic Simulation.}

This computer simulation method aims to analyze atoms' physical movement at the time of binding and nonbinding macromolecule [37]. A five-step standard dynamic cascade protocol in discovery studio was used to study the nature of sophoraflavonone G-SGLT 2 complex. It begins with 1000 steps of very steep descent followed by the 2000 steps of adopted basis minimization followed by the Newton-Raphson method. Further, 0.1 ns heating simulation and $2 \mathrm{fs}$ time step was performed with 50 adjusted velocity frequency. This resulted in input sop g complex, and protein was submitted to equilibration with the same parameters as heating. Finally, the production step was performed at a $0.1 \mathrm{~ns}$ level with NVT condition. The spherical cutoff method was used to calculate the electrostatic energies. RMSD, RMSF AND protein Torsion Angles of the residues were analyzed using the analyze trajectory protocol. The value to calculate the structure's dynamic is mentioned as RMSD (Root Mean Square Deviation); it is a standard measure of the structural distance between coordinates. It measures the average distance between groups of atoms.

\section{Results and Discussion}

\subsection{Homology modeling.}

The proteins' three-dimensional structure was carried out in the Swiss model (Figure 1 A and B). The templates used for homology modeling of human SGLT1 and SGLT2 are mutant Vibrio SGLT (PDB id:2XQ2) [38]. Structure validation was done using the Molprobity 
webserver (Table 2). We found that the ratio between the residues in the most favored region and additional allowed regions is similar for SGLT1 $(76.3 \%)$ and SGLT2 $(74.14 \%)$. The constructed model was energy minimized in DS 2017 using CHARMm. The protein's stereochemical property was carried out with Ramachandran Plot (Figure $1 \mathrm{C}$ and D). validation of protein structure is an important step for in silico analysis. We used the HARMONY server (http://caps.ncbs.res.in/harmony/) to examine the structure and stability of the modeled protein by assigning scores to individual residues. Also, we obtained a good score for total propensity and substitution score (Table 3), which indicates the protein's overall stability. A calibration plot is used to identify folds, misfolds and margin of error. Proteins with the misfolded region have a significant low harmony score and fall in the straight line. The total propensity score and substitution score provide the smoothened score compared to reverse sequence with query sequence (Figure $1 \mathrm{E}$ and F).

Table 2. Comparative analysis and Ramachandran plot analysis of the proteins with Molprobity server.

\begin{tabular}{l|c|c} 
Glucose transporters & SGLT 1 & SGLT 2 \\
\hline Residues in most favored region & 351 & 327 \\
\hline $\begin{array}{l}\text { Residues in the additional allowed } \\
\text { region }\end{array}$ & 460 & 441
\end{tabular}

Table 3. Total Propensity score and Substitution score.

\begin{tabular}{l|c|c|c} 
Proteins & No. of residues & Propensity Score & Substitution Score \\
\hline SGLT 1 & 524 & 2395.3999 & 15291.5254 \\
\hline SGLT 2 & 489 & 2079.40112 & 13857.6582
\end{tabular}

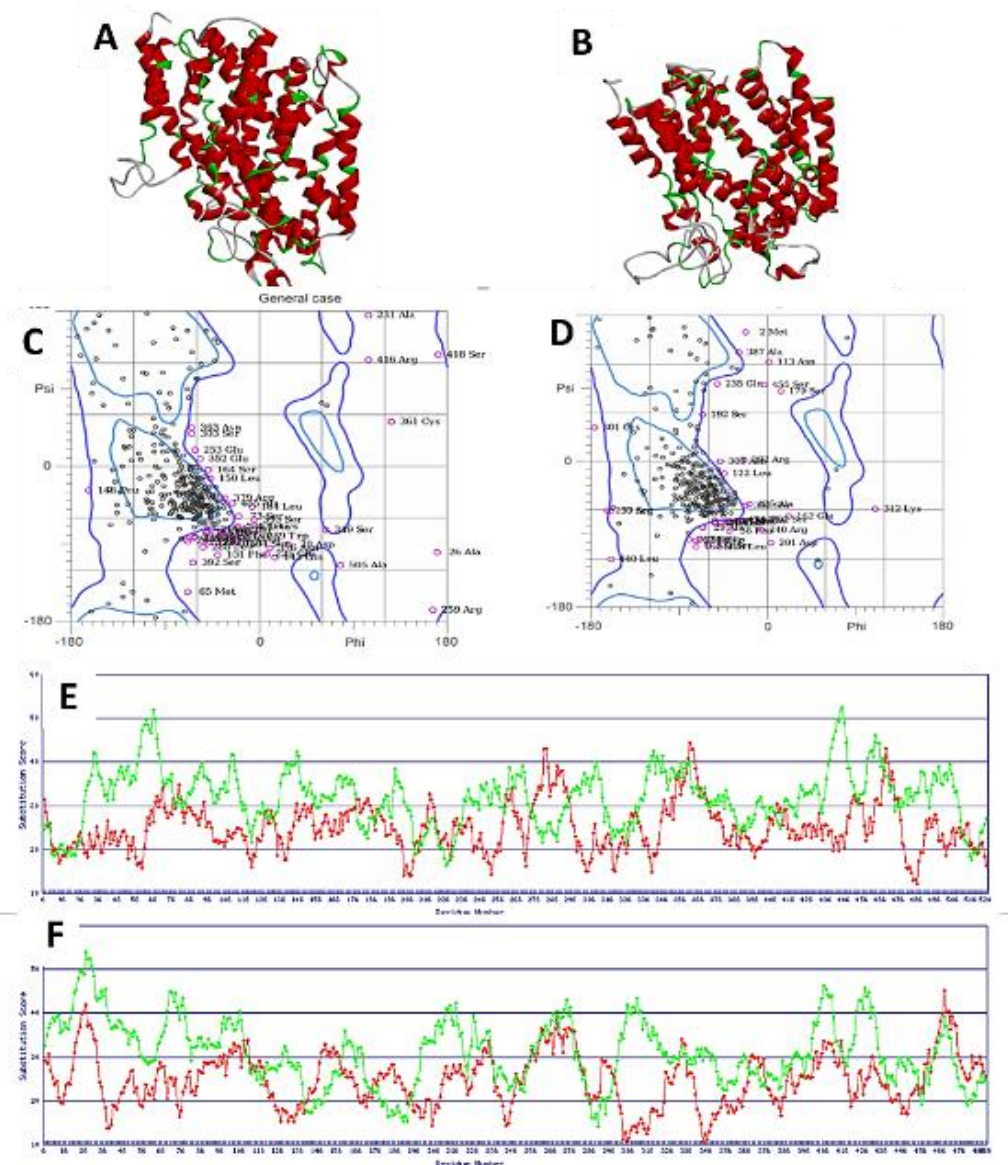

Figure 1. Predicted structure of A)SGLT 1, B) SGLT 2, Ramachandran plot of C) SGLT 1, D) SGLT 2, Validation of protein E) SGLT 1, F) SGLT 2. 


\subsection{Molecular docking.}

To identify the active biological sites of the ligand, molecular docking was performed. This study is performed by using CDOCKER, where CHARMm forcefield is employed for the ligand and the proteins [39]. The CDOCKER score is based on a novel physics-based docking engine (i.e., a unique set of non-bond analyses that includes favorable, unfavorable, and unsatisfied interaction). The CDOCKER algorithm is based on "Structure-based design". The binding site of the modeled proteins is based on the template protein. The sphere's radius was 7 for the binding site of the proteins' interaction (SGLT 1, SGLT 2) and the ligands. CHARMm forcefield was applied to the target and ligands to find out the lowest energy conformation using the SMART minimizer algorithm. The set of 15 ligands (5 drugs and 10 natural compounds) and the receptor proteins (SGLT 1, SGLT 2) were used for the docking. The radius of the binding spheres was set at SGLT 1 ( $\mathrm{X}=1.921, \mathrm{Y}=-31.195, \mathrm{Z}=-56.032)$; SGLT 2 (X $=3.876, \mathrm{Y}=-37.417, \mathrm{Z}=-57.774)$ were submitted to CDOCKER parameters. Ligands with the highest docking scores are shortlisted for pharmacophore analysis. The results show that among 15 ligands, only 13 were docked, and the remaining 2 ligands failed to dock in the active site of the protein. The ligand Sophoraflavanone G has shown the highest libdock score for SGLT $1=-2.55$; compared with other natural compounds which form strong hydrogen bonds, Sophoraflavonone G was found to have Alkyl, Pi-Alkyl, Pi-sigma and amide Pi- stacked Van Der Waals force interaction with the interacting residues of SGLT1. The libdock score for SGLT 2 with Sophoraflavonone G was found to be -4.799 , where strong hydrogen bonds, PiAlkyl, Alkyl, Pi-Cation, and an unfavorable bump interaction was found with the interacting residues. The docking result for the best compound is shown in the below tables (Table 4 and 5) for SGLT1 and SGLT2, respectively. We have selectively shown dapaglifozin and sophoraflavonone G interaction with SGLT 1 (Figure 2) and SGLT 2 (Figure 3).

Table 4. Interaction with SGLT 1.

\begin{tabular}{|c|c|c|c|c|c|c|c|c|}
\hline Name & $\begin{array}{l}\text { C Docker } \\
\text { energy }\end{array}$ & $\begin{array}{l}\text { C Docker } \\
\text { energy } \\
\text { Interaction }\end{array}$ & $\begin{array}{l}\text { Initial } \\
\text { potential } \\
\text { energy }\end{array}$ & $\begin{array}{l}\text { Initial } \\
\text { RMS } \\
\text { gradient }\end{array}$ & $\begin{array}{l}\text { Electrostatic } \\
\text { energy }\end{array}$ & $\begin{array}{l}\text { Potential } \\
\text { energy }\end{array}$ & $\begin{array}{l}\text { Van Der } \\
\text { Waals } \\
\text { energy }\end{array}$ & $\begin{array}{l}\text { RMS } \\
\text { gradient }\end{array}$ \\
\hline Dapagliflozin & -16.1856 & 43.9447 & 43.3229 & 9.24713 & -7.36933 & 21.1992 & -0.30047 & 0.00961 \\
\hline Canagliflozin & -13.7402 & 40.8924 & 56.8803 & 10.7607 & -5.85097 & 24.4546 & 03385 & 0.00904 \\
\hline Luseogliflozin & -19.431 & 51.8952 & 35.051 & 9.55635 & -22.4615 & 8.45956 & 1.01916 & 0.0095 \\
\hline Topogliflozin & +0.759268 & 42.4603 & 63.9008 & 9.30167 & -4.9888 & 394922 & -1.00978 & 0.00919 \\
\hline Empagliflozin & -0.067935 & 48.8322 & 64.0779 & 9.54468 & -11.3074 & 36.5242 & -2.22806 & 0.00948 \\
\hline Variabilin & +27.2427 & 47.1613 & 95.9718 & 16.227 & 1.3013 & 69.6824 & -16.4128 & 0.00914 \\
\hline Sophoraflavanone G & -2.55076 & 42.3333 & 71.5743 & 11.3848 & 5.24414 & 46.8 & -7.50666 & 0.00852 \\
\hline Kurarinone & +5.26431 & 42.6011 & 74.628 & 11.4084 & 1.82874 & 48.3952 & -8.10667 & 0.00966 \\
\hline Formononetin & -15.5973 & 26.4066 & 17.8551 & 11.0142 & -1.23529 & 9.16661 & 4.22027 & 0.00949 \\
\hline Pterocarpin & +19.4484 & 26.0202 & 66.3731 & 23.6777 & -6.0572 & 39.3554 & 7.19842 & 0.00968 \\
\hline Acerogenin A & -15.1623 & 29.9445 & -1.81643 & 6.63012 & -22.9437 & -6.03098 & -1.20927 & 0.00961 \\
\hline Acerogenin B & -17.1741 & 34.3197 & 8.50905 & 6.85452 & -22.9728 & -5.62765 & -2.25999 & 0.00972 \\
\hline Acerogenin $\mathrm{C}$ & -19.3449 & 28.3537 & 2.78925 & 9.51757 & -22.7967 & -11.1551 & -3.30114 & 0.00877 \\
\hline
\end{tabular}




\begin{tabular}{|c|c|c|c|c|c|c|c|c|}
\hline Name & $\begin{array}{l}\text { C Docker } \\
\text { energy }\end{array}$ & $\begin{array}{l}\text { C Docker } \\
\text { energy } \\
\text { Interaction }\end{array}$ & $\begin{array}{l}\text { Initial } \\
\text { potential } \\
\text { energy }\end{array}$ & $\begin{array}{l}\text { Initial } \\
\text { RMS } \\
\text { gradient }\end{array}$ & $\begin{array}{l}\text { Electrostatic } \\
\text { energy }\end{array}$ & $\begin{array}{l}\text { Potential } \\
\text { energy }\end{array}$ & $\begin{array}{l}\text { Van Der } \\
\text { Waals } \\
\text { energy }\end{array}$ & $\begin{array}{l}\text { RMS } \\
\text { gradient }\end{array}$ \\
\hline Gneyulin A & -25.5139 & 74.6637 & 5335.45 & 4575.34 & -32.2179 & 31.787 & 6.82299 & 0.00973 \\
\hline Gneyulin B & -15.4972 & 68.2842 & 5302.57 & 4703.97 & -38.5573 & 19.1332 & 7.87867 & 0.00957 \\
\hline
\end{tabular}

Table 5. Interaction with SGLT 2.

\begin{tabular}{|c|c|c|c|c|c|c|c|c|}
\hline Name & $\begin{array}{l}\text { C Docker } \\
\text { energy }\end{array}$ & $\begin{array}{l}\text { C Docker } \\
\text { energy } \\
\text { Interaction }\end{array}$ & $\begin{array}{l}\text { Initial } \\
\text { potential } \\
\text { energy }\end{array}$ & $\begin{array}{l}\text { Initial } \\
\text { RMS } \\
\text { gradient }\end{array}$ & $\begin{array}{l}\text { Electrostatic } \\
\text { energy }\end{array}$ & $\begin{array}{l}\text { Potential } \\
\text { energy }\end{array}$ & $\begin{array}{l}\text { Van Der } \\
\text { Waals } \\
\text { energy }\end{array}$ & $\begin{array}{l}\text { RMS } \\
\text { gradient }\end{array}$ \\
\hline Dapagliflozin & -13.0169 & 52.6356 & 46.3229 & 9.24713 & -7.36933 & 21.1992 & -0.30047 & 0.00961 \\
\hline Canagliflozin & -19.4977 & 47.3875 & 56.8803 & 10.7607 & -5.85097 & 24.4546 & 0.3385 & 0.00904 \\
\hline Luseogliflozin & -18.6059 & 47.9363 & 35.051 & 9.55635 & -22.4615 & 8.45956 & 1.01916 & 0.0095 \\
\hline Topogliflozin & -0.517491 & 46.4127 & 63.9008 & 9.30167 & -4.9888 & 39.4922 & -1.00978 & 0.00919 \\
\hline Empagliflozin & -0.378219 & 49.2695 & 64.0779 & 9.54468 & -11.3074 & 36.5242 & -2.22806 & 0.00948 \\
\hline Variabilin & +32.2813 & 48.5525 & 63.9008 & 16.227 & 1.3013 & 69.6824 & -16.4128 & 0.00914 \\
\hline Sophoraflavanone G & -4.79975 & 49.2259 & 71.5743 & 11.3848 & 5.24414 & 46.8 & -7.50666 & 0.00852 \\
\hline Kurarinone & -1.82271 & 49.6274 & 74.628 & 11.4084 & 1.82874 & 48.3952 & -2.01667 & 0.00966 \\
\hline Formononetin & -22.2949 & 32.8885 & 17.8551 & 11.0142 & -1.23529 & 9.16661 & 4.22027 & 0.00949 \\
\hline Pterocarpin & +15.079 & 30.4889 & 66.3731 & 23.6777 & -6.0572 & 39.3554 & 7.19842 & 0.00968 \\
\hline Acerogenin A & -14.6421 & 30.4329 & -1.81643 & 6.63012 & -22.9437 & -6.03098 & -1.20927 & 0.00961 \\
\hline Acerogenin B & -13.958 & 31.6208 & 8.50905 & 6.85452 & -22.9728 & -5.62765 & -2.25999 & 0.00972 \\
\hline Acerogenin $\mathrm{C}$ & -22.103 & 33.949 & 2.78925 & 9.51757 & -22.7967 & -11.1551 & -3.30114 & 0.00877 \\
\hline Gneyulin A & +3.62908 & 64.3098 & 5335.45 & 4575.34 & -32.2179 & 37.787 & 6.82299 & 0.00973 \\
\hline Gneyulin B & -6.6668 & 68.7939 & 5302.57 & 4703.97 & -38.5573 & 19.1332 & 7.87867 & 0.00957 \\
\hline
\end{tabular}
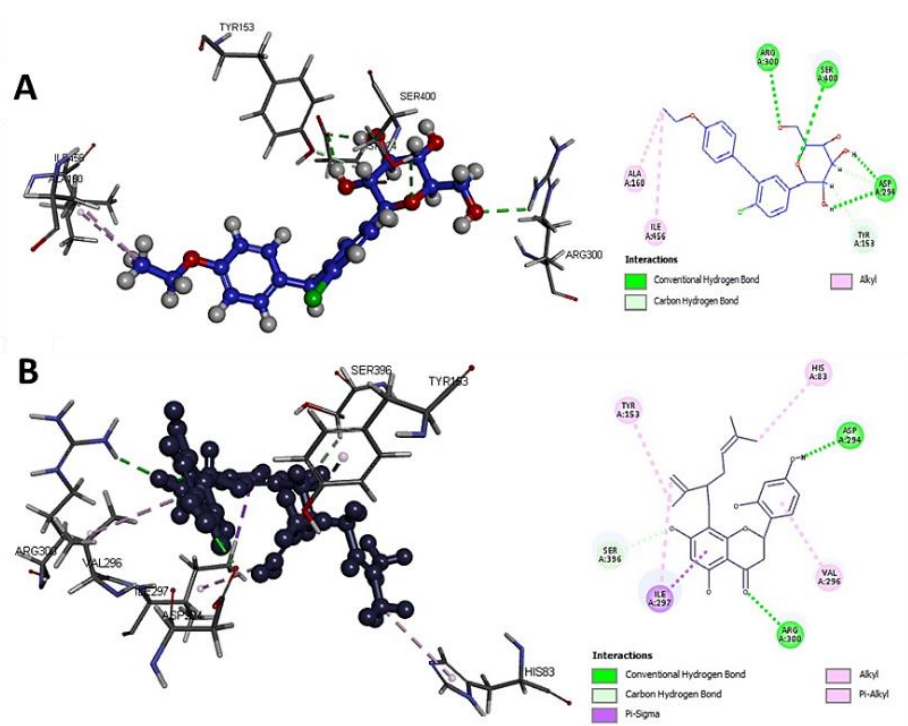

Figure 2. (A) Interaction of Dapagliflozin with SGLT 1.3D and 2D interaction view of protein and ligand complex and (B) Interaction of Sophoraflavanone G with SGLT 1, 3D and 2D interaction view of protein and ligand complex. 

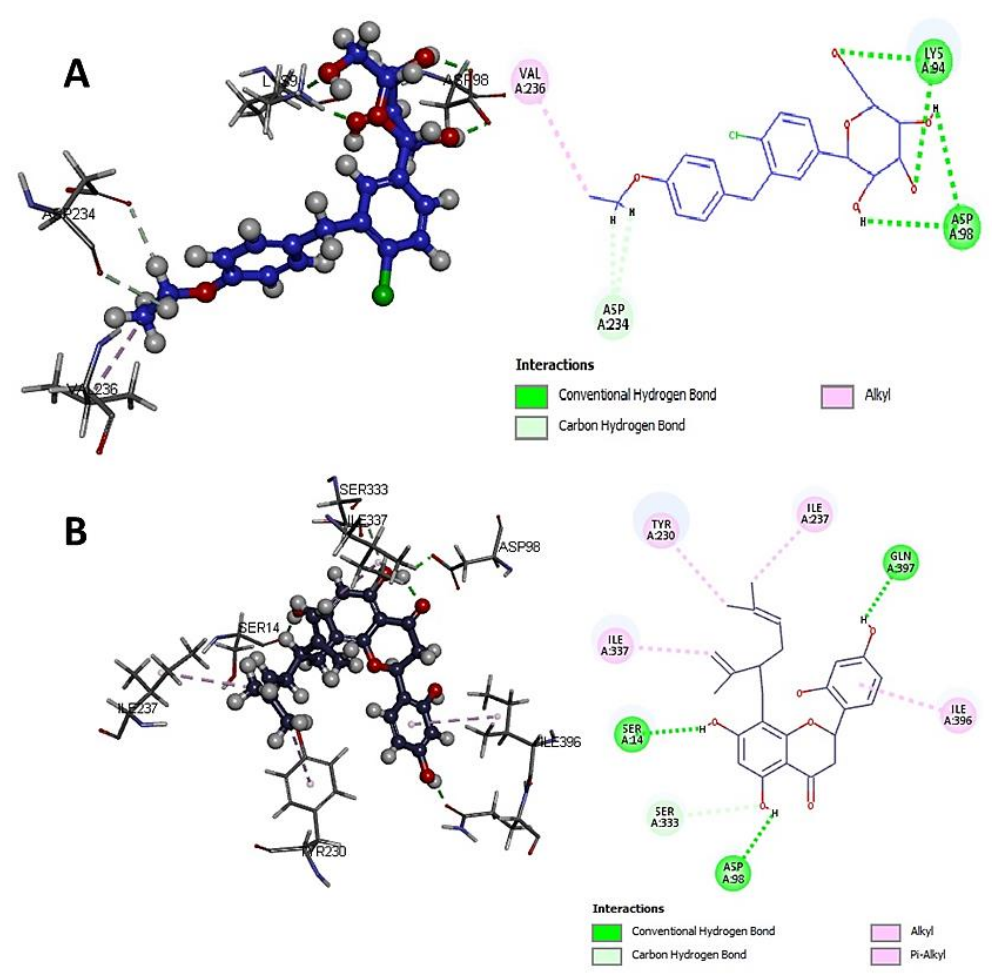

Figure 3. (A) Interaction of Dapagliflozin with SGLT 2, 3D and 2D interaction view of protein and ligand complex. (B)Interaction of Sophoraflavanone G with SGLT 2, 3D and 2D interaction view of protein and ligand complex.

\subsection{ADMET-SAR.}

Acute oral toxicity refers to the adverse effect observed within $24 \mathrm{~h}$ of oral or dermal administration of single or multiple doses of a given substance. LD50 or median lethal dose was divided into four categories. Categories I contain the compound $\leq 50 \mathrm{mg} / \mathrm{kg}$. Categories II contains compound $>50 \mathrm{mg} / \mathrm{kg}$ but $<500 \mathrm{mg} / \mathrm{kg}$. Category III LD50 contains $>500 \mathrm{mg} / \mathrm{kg}$ but $<5000 \mathrm{mg} / \mathrm{kg}$, and Category IV LD50 contains $>5000 \mathrm{mg} / \mathrm{kg}$. Bio-degradation is to check the drug's breakdown, which is a chemical reaction that involves the collision of molecules. Human intestinal absorption if the compound with HIA\% is less than $30 \%$ it is labeled as HIA-, otherwise labeled as HIA+. In Table 6, the ADMET score for 5 drugs and 10 natural compounds is mentioned. Considering all the factors, Soporaflavonone G was selected for further analysis.

\begin{tabular}{|c|c|c|c|c|c|c|c|}
\hline $\begin{array}{l}\text { Chemical Drug } \\
\text { and natural } \\
\text { compounds }\end{array}$ & $\begin{array}{l}\text { Acute Oral } \\
\text { Toxicity } \\
\text { (Kg/mol) }\end{array}$ & $\begin{array}{l}\text { Bio- } \\
\text { degradatio } \\
\text { n }\end{array}$ & $\begin{array}{l}\text { Human Oral } \\
\text { Bioavailability }\end{array}$ & $\begin{array}{l}\text { Human } \\
\text { Intestinal } \\
\text { Absorption }\end{array}$ & $\begin{array}{l}\text { CYP2D6 } \\
\text { Inhibitor }\end{array}$ & $\begin{array}{l}\text { Blood-Brain } \\
\text { Barrier (BBB) }\end{array}$ & $\begin{array}{l}\text { Solubility } \\
(\log S)\end{array}$ \\
\hline Dapagliflozin & 2.776 & - & $-(0.6714)$ & $+(0.9297)$ & $-(0.8768)$ & $+(0.9557)$ & -3.0847 \\
\hline Canagliflozin & 2.901 & - & - $(0.5429)$ & $+(0.8753)$ & - $(0.8683)$ & $+(0.9681)$ & -2.8768 \\
\hline Luseogliflozin & 2.284 & - & $+(0.5286)$ & $+(0.9338)$ & $-(0.9215)$ & $+(0.9460)$ & -2.4706 \\
\hline Tofogliflozin & 2.762 & - & $-(0.5143)$ & $+(0.6489)$ & $-(0.9401)$ & $+(0.8578)$ & -1.9281 \\
\hline Empagliflozin & 3.114 & - & $-(0.7000)$ & $+(0.9094)$ & - $(0.7888)$ & $+(0.9685)$ & -2.7518 \\
\hline Variabilin & 2.302 & - & $-(0.6571)$ & $+(0.9751)$ & $-(0.8811)$ & $+(0.9491)$ & -3.5814 \\
\hline
\end{tabular}




\begin{tabular}{l|l|l|l|l|l|l|l}
$\begin{array}{l}\text { Chemical Drug } \\
\text { and natural } \\
\text { compounds }\end{array}$ & $\begin{array}{l}\text { Acute Oral } \\
\text { Toxicity } \\
(\text { Kg/mol) }\end{array}$ & $\begin{array}{l}\text { Bio- } \\
\text { degradatio } \\
\mathbf{n}\end{array}$ & $\begin{array}{l}\text { Human Oral } \\
\text { Bioavailability }\end{array}$ & $\begin{array}{l}\text { Human } \\
\text { Intestinal } \\
\text { Absorption }\end{array}$ & $\begin{array}{l}\text { CYP2D6 } \\
\text { Inhibitor }\end{array}$ & $\begin{array}{l}\text { Blood-Brain } \\
\text { Barrier (BBB) }\end{array}$ & $\begin{array}{l}\text { Solubility } \\
(\text { Log S) }\end{array}$ \\
\hline $\begin{array}{l}\text { Sophoraflavanone } \\
\text { G }\end{array}$ & 2.878 & - & $-(0.6143)$ & $+(0.9951)$ & $-(0.6860)$ & $-(0.45)$ & -3.8950 \\
\hline Kurarinone & 2.544 & - & $-(0.6143)$ & $+(0.9965)$ & $+(0.7350)$ & $-(0.3578)$ & -3.9253 \\
\hline Formononetin & 1.606 & - & $+(0.5714)$ & $+(0.9911)$ & $-(0.8998)$ & $-(0.3715)$ & -3.4575 \\
\hline Pterocarpin & 1.454 & - & $-(0.5857)$ & $+(0.9906)$ & $+(0.9395)$ & $+(0.9282)$ & -3.3129 \\
\hline Acerogenin A & 2.245 & - & $-(0.5714)$ & $+(0.9490)$ & $-(0.9330)$ & $+(0.8140)$ & -2.4715 \\
\hline Acerogenin B & 2.151 & - & $-(0.5714)$ & $+(0.9490)$ & $-(0.9330)$ & $+(0.8140)$ & -2.4715 \\
\hline Acerogenin C & 1.742 & - & $-(0.5429)$ & $+(0.9528)$ & $-(0.9626)$ & $-(0.2408)$ & -2.3657 \\
\hline Gneyulin A & 1.911 & - & $-(0.7286)$ & $+(0.9923)$ & $-(0.8256)$ & $-(0.2372)$ & -3.6052 \\
\hline Gneyulin B & 2.351 & - & $-(0.7286)$ & $+(0.9940)$ & $-(0.8110)$ & $-(0.2472)$ & -3.3455
\end{tabular}

\subsection{Molecular dynamic simulation.}

The result of protein and docked complex standard dynamic simulation studies showed that the energy and RMS gradient variations. The potential energy in the production step for the protein and the complex was found to be $-23523.160 \mathrm{kcal} / \mathrm{mol}$ and $-23375.509 \mathrm{kcal} / \mathrm{mol}$, respectively. The energy difference between protein and drug complex was negligible, which proved the drug complex was stable to inhibit the protein completely.

The total energy of protein starts from $-17525.447 \mathrm{kcal} / \mathrm{mol}$ at the beginning time; further, it reduced to the local minima with the energy level of $-17812.447 \mathrm{kcal} / \mathrm{mol}$ at the time of 300 ps time (Figure 4). Similarly, the drug complex's final energy was found to be $17799.125 \mathrm{kcal} / \mathrm{mol}$ (Figure 5).

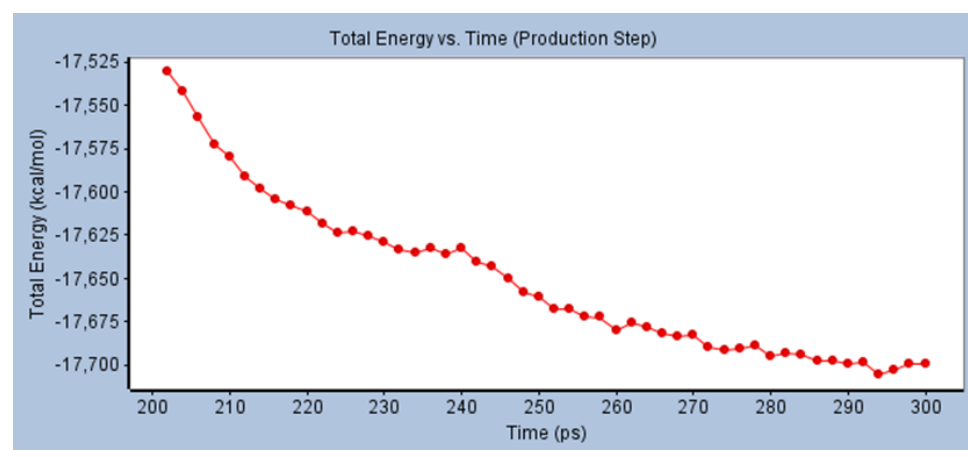

Figure 4. The total energy changes at different time intervals for the protein.

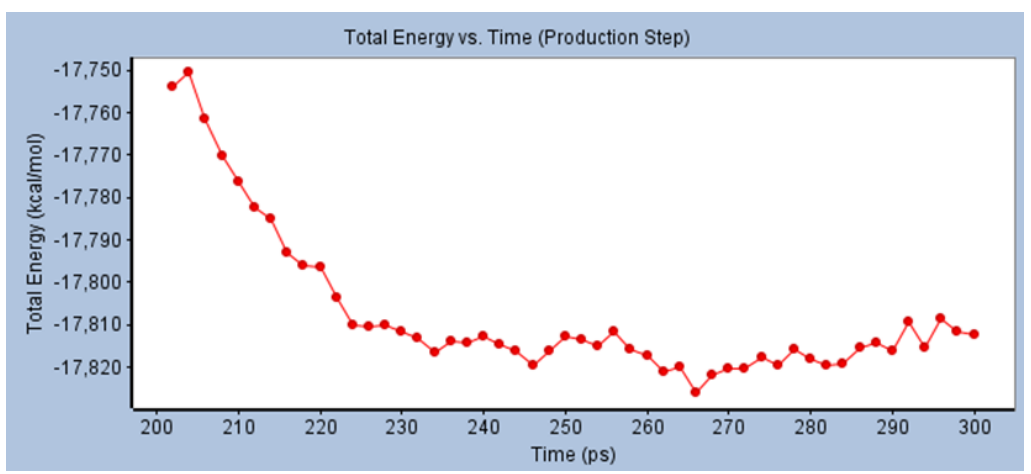

Figure 5. The total energy changes at different time intervals for the protein and drug complex. 


\subsection{Trajectory analysis.}

Trajectory analysis protocol run resulted in the RMSD and RMSF values for the 50 confirmation of SGLT 2 and SGLT 2- sophoraflavonone G complex. The analysis of Figure 6 revealed that the natural compound interacted well and did not make any energy changes of residues of the protein. Drug molecules alter the confirmation of two non-binding site amino acids Ser1 and Met138 (Figure 6 a-d). This does not make any fluctuations of any other residues of the protein confirmed the complex's stability.

This overall dynamic simulation analysis concludes that the drug molecule forms a stable complex with the protein and is possible to completely inhibit the target protein.
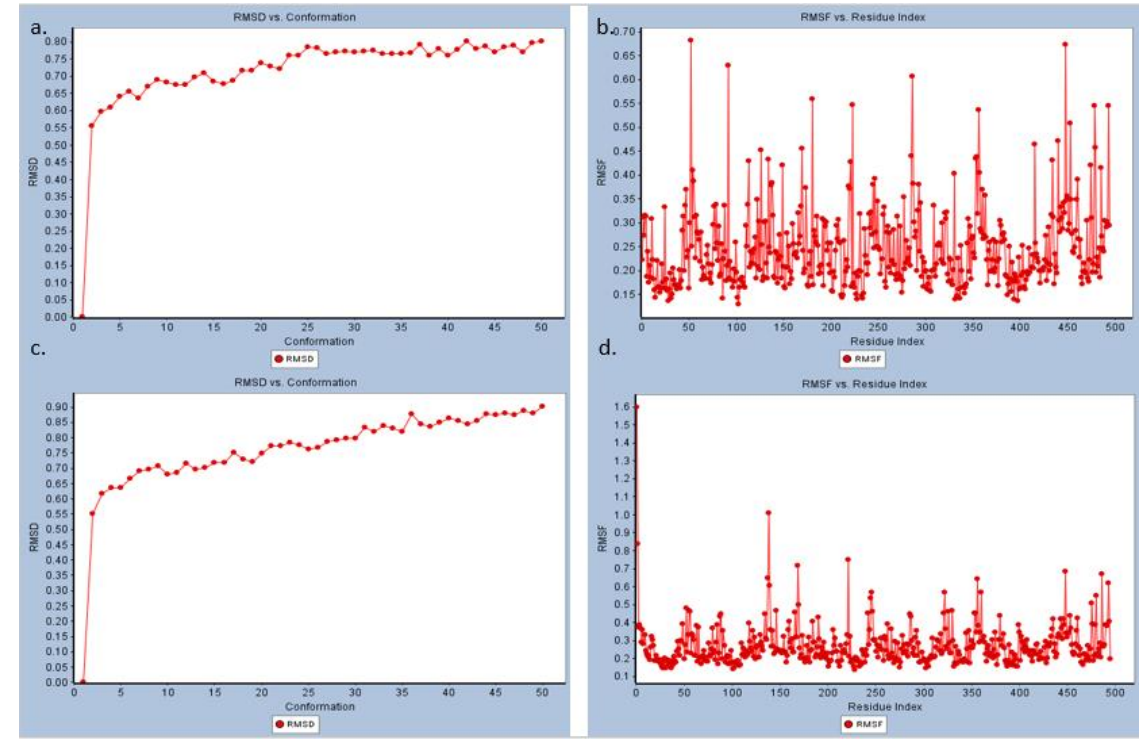

Figure 6. Trajectory analysis of 50 confirmation of protein and drug-protein complex. a. RMSD value of 50 protein. b. RMS fluctuations of residues of the protein. c. RMSD value of 50 protein and drug complex. b. RMS fluctuations of residues of protein and drug complex.

\section{Conclusions}

The modeled human SGLT 1 and 2 were docked with selected gliflozin drugs and natural compounds. The purpose of docking was to predict the structure of the ligands constraints of receptor binding sites and estimate binding strength. The binding mode of sodium-glucose transporters with bioactive compounds was investigated by doing computational analysis using CDOCKER. The docking analysis results were described in Table 4 and 5, and Sophoraflavanone G showed a good docking score because the lower value of free energy of binding validates a strong and favorable bond, which is preferred for best docking study. So, the docking score between SGLTs and Sophoraflavanone G is the most favorable conformations with compared standard drugs. The ADME analysis shown in Table 3-4 shows that the selected physicochemical properties are known to absorption and bioavailability. Sophoraflavanone $G$ satisfied all the ADMET properties as a drug-like potential. Molecular Dynamic simulation revealed stable complex formation between SGLT 2 and sophoraflavonone G (Figure 4-6), which indicates sophoraflavonone $\mathrm{G}$ can be a good alternative SGLT 2 inhibitor.

\section{Funding}

This research received no external funding. 


\section{Acknowledgments}

This research has no acknowledgment.

\section{Conflicts of Interest}

The authors declare no conflict of interest.

\section{References}

1. Roden, M.; Shulman, G.I. The integrative biology of type 2 diabetes. Nature 2019, 576, 51-60, https://doi.org/10.1038/s41586-019-1797-8.

2. Gregg, E.W.; Sattar, N.; Ali, M.K. The changing face of diabetes complications. The Lancet Diabetes \& Endocrinology 2016, 4, 537-547, https://doi.org/10.1016/S2213-8587(16)30010-9.

3. Swinnen, S.G.; Hoekstra, J.B.; DeVries, J.H. Insulin Therapy for Type 2 Diabetes. Diabetes Care 2009, 32 , S253-9, https://doi.org/10.2337/dc09-S318.

4. Ashcroft, F.M. Mechanisms of the glycaemic effects of sulfonylureas. Horm. Metab. Res 1996, 28, 456-63, https://doi.org/10.1055/s-2007-979837.

5. van de Laar, F.A. Alpha-glucosidase inhibitors in the early treatment of type 2 diabetes. Vasc Health Risk Manag 2008, 4, 1189-95, https://doi.org/10.2147/vhrm.s3119.

6. Miller, R.A.; Chu, Q.; Xie, J.; Foretz, M.; Viollet, B.; Birnbaum, M.J. Biguanides suppress hepatic glucagon signalling by decreasing production of cyclic AMP. Nature 2013, 494, 256-260, https://doi.org/10.1038/nature11808.

7. Kahn, C.R.; Chen, L.; Cohen, S.E. Unraveling the mechanism of action of thiazolidinediones. The Journal of Clinical Investigation 2000, 106, 1305-1307, https://doi.org/10.1172/JCI11705.

8. Lamos, E.M.; Levitt, D.L.; Munir, K.M. A review of dopamine agonist therapy in type 2 diabetes and effects on cardio-metabolic parameters. Primary Care Diabetes 2016, 10, 60-65, https://doi.org/10.1016/j.pcd.2015.10.008.

9. Weber, A.E. Dipeptidyl Peptidase IV Inhibitors for the Treatment of Diabetes. Journal of Medicinal Chemistry 2004, 47, 4135-4141, https://doi.org/10.1021/jm030628v.

10. Xue, J.; Wang, C.; Pan, C.; Xing, H.; Xu, L.; Chen, X.; Wang, X.; Wang, N. Effect of DPP-4 inhibitor on elderly patients with T2DM combined with MCI. Exp Ther Med 2020, 19, 1356-1362, https://doi.org/10.3892/etm.2019.8339.

11. Banerjee, S. Nanoparticle-Based Delivery of Phytochemical Compounds Against Major Maladies: Cancer, Diabetes, and Cardiovascular Disease. In: Plant-derived Bioactives: Production, Properties and Therapeutic Applications. eds. Swamy, M.K. Springer Singapore: Singapore, 2020; pp. 591-619, https://doi.org/10.1007/978-981-15-1761-7_25.

12. Vallon, V. The mechanisms and therapeutic potential of SGLT2 inhibitors in diabetes mellitus. Annu. Rev. Med 2015, 66, 255-70, https://doi.org/10.1146/annurev-med-051013-110046.

13. Scheen, A.J. Sodium-glucose co-transporter type 2 inhibitors for the treatment of type 2 diabetes mellitus. Nature Reviews Endocrinology 2020, 16, 556-577, https://doi.org/10.1038/s41574-020-0392-2.

14. Harada, N.; Inagaki, N. Role of sodium-glucose transporters in glucose uptake of the intestine and kidney. Journal of Diabetes Investigation 2012, 3, 352-353, https://doi.org/10.1111/j.2040-1124.2012.00227.x.

15. Hsia, D.S.; Grove, O.; Cefalu, W.T. An update on sodium-glucose co-transporter-2 inhibitors for the treatment of diabetes mellitus. Curr. Opin. Endocrinol. Diabetes Obes 2017, 24, 73-79, https://doi.org/10.1097/MED.0000000000000311.

16. Ankit, G.; Sheenu, M.; Monika; Richa, D.; Neelima, D. Turning Foes to Friends: Knocking Down Diabetes Associated SGLT2 Transporters and Sustaining Life. Current Diabetes Reviews 2020, 16, 716-732, https://doi.org/10.2174/1573399816666200117155016.

17. Kitamura, K.; Hayashi, K.; Ito, S.; Hoshina, Y.; Sakai, M.; Yoshino, K.; Endo, K.; Fujitani, S.; Suzuki, T. Effects of SGLT2 inhibitors on eGFR in type 2 diabetic patients-the role of anti-diabetic and antihypertensive medications. Hypertens. Res 2020. https://doi.org/10.1038/s41440-020-00590-1.

18. Mahakpreet, S.; Anoop, K. Risks Associated with SGLT2 Inhibitors: An Overview. Current Drug Safety 2018, 13, 84-91, https://doi.org/10.2174/1574886313666180226103408.

19. Fathi, A.; Vickneson, K.; Singh, J.S. SGLT2-inhibitors; more than just glycosuria and diuresis. Heart Failure Reviews 2020, https://doi.org/10.1007/s10741-020-10038-w.

20. Yang, S.-C.; Hsu, C.-Y.; Chou, W.-L.; Fang, J.-Y.; Chuang, S.-Y. Bioactive Agent Discovery from the Natural Compounds for the Treatment of Type 2 Diabetes Rat Model. Molecules 2020, 25, https://doi.org/10.3390/molecules25235713.

21. Shaik Ibrahim, K.; Arifullah, M.; Kokkanti, M. Novel Phytochemical Constituents and their Potential to Manage Diabetes. Current Pharmaceutical Design 2021, 27, 1-14, https://doi.org/10.2174/1381612826666201222154159. 
22. Tupas, G.D.; Otero, M.C.B.; Ebhohimen, I.E.; Egbuna, C.; Aslam, M. Chapter 8 - Anti-diabetic lead compounds and targets for drug development. In: Phytochemicals as Lead Compounds for New Drug Discovery. Egbuna, C.; Kumar, S.; Ifemeje, J.C.; Ezzat, S.M.; Kaliyaperumal, S. Eds. Elsevier: 2020; pp. 127-141, https://doi.org/10.1016/B978-0-12-817890-4.00008-1.

23. Diab, K.A.; Fahmy, M.A.; Hassan, E.M.; Hassan, Z.M.; Omara, E.A.; Abdel-Samie, N.S. Inhibitory activity of black mulberry (Morus nigra) extract against testicular, liver and kidney toxicity induced by paracetamol in mice. Molecular Biology Reports 2020, 47, 1733-1749, https://doi.org/10.1007/s11033-020-05265-1.

24. Shah, N.A.; Khan, M.R.; Nigussie, D. Phytochemical investigation and nephroprotective potential of Sida cordata in rat. BMC Complementary and Alternative Medicine 2017, 17, https://doi.org/10.1186/s12906017-1896-8.

25. Blaschek, W. Natural Products as Lead Compounds for Sodium Glucose Cotransporter (SGLT) Inhibitors. Planta Med 2017, 83, 985-993, https://doi.org/10.1055/s-0043-106050.

26. Kshirsagar, R.P.; Kulkarni, A.A.; Chouthe, R.S.; Pathan, S.K.; Une, H.D.; Reddy, G.B.; Diwan, P.V.; Ansari, S.A.; Sangshetti, J.N. SGLT inhibitors as anti-diabetic agents: a comprehensive review. RSC Advances 2020, 10, 1733-1756, https://doi.org/10.1039/C9RA08706K.

27. Feng, R.; Dong, L.; Wang, L.; Xu, Y.; Lu, H.; Zhang, J. Development of sodium glucose co-transporter 2 (SGLT2) inhibitors with novel structure by molecular docking and dynamics simulation. Journal of Molecular Modeling 2019, 25, https://doi.org/10.1007/s00894-019-4067-7.

28. Mercado-Camargo, J.; Cervantes-Ceballos, L.; Vivas-Reyes, R.; Pedretti, A.; Serrano-García, M.L.; GómezEstrada, H. Homology Modeling of Leishmanolysin (gp63) from Leishmania panamensis and Molecular Docking of Flavonoids. ACS Omega 2020, 5, 14741-14749, https://doi.org/10.1021/acsomega.0c01584.

29. Choi, C.-I. Sodium-Glucose Cotransporter 2 (SGLT2) Inhibitors from Natural Products: Discovery of NextGeneration Antihyperglycemic Agents. Molecules 2016, 21, https://doi.org/10.3390/molecules21091136.

30. Shehadi, I.A.; Rashdan, H.R.M.; Abdelmonsef, A.H. Homology Modeling and Virtual Screening Studies of Antigen MLAA-42 Protein: Identification of Novel Drug Candidates against Leukemia-An In Silico Approach. Computational and Mathematical Methods in Medicine 2020, 2020, https://doi.org/10.1155/2020/8196147.

31. Mosina, N.L.; Schubert, W.-D.; Cowan, D.A. Characterization and homology modelling of a novel multimodular and multi-functional Paenibacillus mucilaginosus glycoside hydrolase. Extremophiles 2019, 23, 681-686, https://doi.org/10.1007/s00792-019-01121-8.

32. Puzari, M.; Chetia, P. Virtual high-throughput screening and simulation studies of compounds from selected traditionally important medicinal plants for the identification of potential inhibitors of AcrB. Journal of Biomolecular Structure and Dynamics 2020, 1-9, https://doi.org/10.1080/07391102.2020.1858162.

33. Brooks, B.R.; Brooks Iii, C.L.; Mackerell Jr, A.D.; Nilsson, L.; Petrella, R.J.; Roux, B.; Won, Y.; Archontis, G.; Bartels, C.; Boresch, S.; Caflisch, A.; Caves, L.; Cui, Q.; Dinner, A.R.; Feig, M.; Fischer, S.; Gao, J.; Hodoscek, M.; Im, W.; Kuczera, K.; Lazaridis, T.; Ma, J.; Ovchinnikov, V.; Paci, E.; Pastor, R.W.; Post, C.B.; Pu, J.Z.; Schaefer, M.; Tidor, B.; Venable, R.M.; Woodcock, H.L.; Wu, X.; Yang, W.; York, D.M.; Karplus, M. CHARMM: The biomolecular simulation program. Journal of Computational Chemistry 2009, 30, 1545-1614, https://doi.org/10.1002/jcc.21287.

34. Cheng, F.; Li, W.; Zhou, Y.; Shen, J.; Wu, Z.; Liu, G.; Lee, P.W.; Tang, Y. admetSAR: A Comprehensive Source and Free Tool for Assessment of Chemical ADMET Properties. Journal of Chemical Information and Modeling 2012, 52, 3099-3105, https://doi.org/10.1021/ci300367a.

35. Taroncher, M.; Rodríguez-Carrasco, Y.; Ruiz, M.-J. Interactions between T-2 toxin and its metabolites in HepG2 cells and in silico approach. Food and Chemical Toxicology 2021, 148, https://doi.org/10.1016/j.fct.2020.111942.

36. Ashish, S.; Ghanshyam, P.; Avinash Kumar, S. In Silico Discovery of Novel Flavonoids as poly ADP Ribose Polymerase (PARP) Inhibitors. Current Computer-Aided Drug Design 2020, 16, 1-7, https://doi.org/10.2174/1573409916666200408082858.

37. Wang, W.; Gan, N.; Sun, Q.; Wu, D.; Gan, R.; Zhang, M.; Tang, P.; Li, H. Study on the interaction of ertugliflozin with human serum albumin in vitro by multispectroscopic methods, molecular docking, and molecular dynamics simulation. Spectrochimica Acta Part A: Molecular and Biomolecular Spectroscopy 2019, 219, 83-90, https://doi.org/10.1016/j.saa.2019.04.047.

38. Shakil, S. Molecular Interaction of Anti-Diabetic Drugs With Acetylcholinesterase and Sodium Glucose CoTransporter 2. Journal of cellular biochemistry 2017, 118, 3855-3865, https://doi.org/10.1002/jcb.26036.

39. Wu, G.; Robertson, D.H.; Brooks Iii, C.L.; Vieth, M. Detailed analysis of grid-based molecular docking: A case study of CDOCKER-A CHARMm-based MD docking algorithm. Journal of Computational Chemistry 2003, 24, 1549-1562, https://doi.org/10.1002/jcc.10306. 